\title{
A mixed bag: Differential influences of oxygenation and perfusion on brain development in congenital heart disease
}

\author{
Caitlin K. Rollins, MD
}

From the Departments of Neurology, Boston Children's Hospital and Harvard Medical School, Boston, Mass. Funding from a K12 NS079414 from the National Institute of Neurological Disorders and Stroke and a Scholar Award from the Pediatric Heart Network (PHN) supported by the National Heart, Lung, and Blood Institute of the NIH under Award Number U10HL068270 is acknowledged. The content is solely the responsibility of the author and does not necessarily represent the official views of the National Institutes of Health.

Disclosures: Author has nothing to disclose with regard to commercial support.

Received for publication June 19, 2016; accepted for publication June 21, 2016; available ahead of print July 20, 2016.

Address for reprints: Caitlin K. Rollins, MD, Department of Neurology, Boston Children's Hospital, 300 Longwood Ave, Boston, MA 02115 (E-mail: caitlin.rollins@ childrens.harvard.edu).

J Thorac Cardiovasc Surg 2016;152:960-1

$0022-5223 / \$ 36.00$

Copyright (C 2016 by The American Association for Thoracic Surgery

http://dx.doi.org/10.1016/j.jtcvs.2016.06.029

It is now established that neonates with congenital heart disease (CHD) have impaired brain growth and maturation before surgery. Smaller brain volumes and less-mature patterns of macro- and microstructural brain development are seen before and after birth. ${ }^{1-3}$ Multiple factors have been implicated in this pathway, including innate genetic abnormalities, disturbed placental health, and direct trophic influences of reduced cerebral oxygenation and perfusion. ${ }^{4-6}$

Lim and colleagues ${ }^{7}$ investigated the latter, using cine phase-contrast imaging to measure cerebral blood flow and calculate oxygen delivery in neonates with various forms of CHD preoperatively. Compared with healthy neonates, those with CHD had similar cerebral blood flow but reduced oxygen delivery. These differences were most apparent in the neonates with single-ventricle physiology and transposition of the great arteries. Further, reduced oxygen delivery was associated with a smaller and less-mature brain. Previous work from this group similarly suggested relatively preserved cerebral blood flow in the late prenatal period. ${ }^{6}$ Their findings differ from other studies using near-infrared spectroscopy and pulsed arterial spin-label perfusion imaging that show reduced cerebral blood flow in cohorts more heavily weighted with obstructive left-sided lesions such as hypoplastic left heart syndrome. ${ }^{8,9}$

Although technical differences may in part account for the discrepancy, the contrasting results likely also reflect that the relative contributions of abnormal cerebral blood flow and oxygenation differ among forms of CHD. In transposition of the great arteries, one would expect preserved cerebral blood flow with reduced oxygenation as the authors found. On the other hand, in severe left outflow tract obstructions such as hypoplastic left heart syndrome with aortic atresia, one might expect reduced cerebral flow with less marked oxygenation differences. Doppler investigations similarly

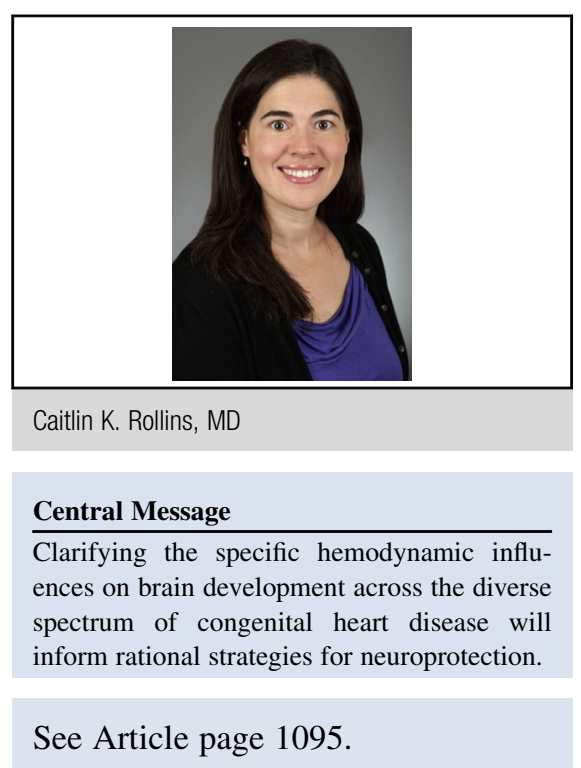

indicate variable cerebrovascular compensatory responses depending on the type of heart disease evaluated. ${ }^{10}$ Although single-center studies often necessarily include various forms of CHD due to sample size limitations, CHD is heterogeneous, and different hemodynamic factors may dominate in different lesions. Further investigations using standardized techniques across large multicenter cohorts to allow subgroup analyses are critical to integrate cerebral findings with cardiac anatomy and establish the pathophysiologic processes operating in different disease forms.

Efforts that enhance technical capabilities of measuring cerebral blood flow and oxygenation in CHD are central to improving cardiac brain care. They may suggest practice modifications to improve neurologic outcome, such as earlier surgery for patients with low cerebral oxygen delivery. More broadly, coupling these measures with detailed structural neuroimaging data and performing longitudinal measurements will clarify the timing of onset and causal pathways of brain disease in CHD and illuminate potential preventive strategies. As the field moves toward neuroprotection trials, direct measures of cerebral perfusion and oxygen delivery are important early outcomes, because neurodevelopment takes years to establish.

In $\mathrm{CHD}$, we have a unique opportunity to identify patients at risk for brain injury before and/or during the ischemic insult. Clarifying the specific physiologic derangements that affect brain development across the 
diverse spectrum of CHD will promote rational strategies to mitigate these deleterious influences on the brain.

\section{References}

1. Limperopoulos C, Tworetzky W, McElhinney DB, Newburger JW, Brown DW, Robertson RL Jr, et al. Brain volume and metabolism in fetuses with congenital heart disease: evaluation with quantitative magnetic resonance imaging and spectroscopy. Circulation. 2010;121:26-33.

2. Licht DJ, Shera DM, Clancy RR, Wernovsky G, Montenegro LM, Nicolson SC, et al. Brain maturation is delayed in infants with complex congenital heart defects. J Thorac Cardiovasc Surg. 2009;137:529-36.

3. Miller SP, McQuillen PS, Hamrick S, Xu D, Glidden DV, Charlton N, et al. Abnormal brain development in newborns with congenital heart disease. N Engl J Med. 2007:357:1928-38.

4. Homsy J, Zaidi S, Shen Y, Ware JS, Samocha KE, Karczewski KJ, et al. De novo mutations in congenital heart disease with neurodevelopmental and other congenital anomalies. Science. 2015;350:1262-6.
5. Andescavage N, Yarish A, Donofrio M, Bulas D, Evangelou I, Vezina G, et al. 3-D volumetric MRI evaluation of the placenta in fetuses with complex congenital heart disease. Placenta. 2015;36:1024-30.

6. Sun L, Macgowan CK, Sled JG, Yoo SJ, Manlhiot C, Porayette P, et al. Reduced fetal cerebral oxygen consumption is associated with smaller brain size in fetuses with congenital heart disease. Circulation. 2015;131:1313-23.

7. Lim JM, Kingdom T, Saini B, Chau V, Post M, Blaser S, et al. Cerebral oxygen delivery is reduced in newborns with congenital heart disease. J Thorac Cardiovasc Surg. 2016;152:1095-103.

8. Licht DJ, Wang J, Silvestre DW, Nicolson SC, Montenegro LM, Wernovsky G, et al. Preoperative cerebral blood flow is diminished in neonates with severe congenital heart defects. J Thorac Cardiovasc Surg. 2004;128:841-9.

9. Dehaes M, Cheng HH, Buckley EM, Lin PY, Ferradal S, Williams K, et al. Perioperative cerebral hemodynamics and oxygen metabolism in neonates with single-ventricle physiology. Biomed Opt Express. 2015;6:4749-67.

10. Kaltman JR, Di H, Tian Z, Rychik J. Impact of congenital heart disease on cerebrovascular blood flow dynamics in the fetus. Ultrasound Obstet Gynecol. 2005;25:32-6. 